\title{
Study habit and academic performance of Christian Religious Studies students in Federal College of Education, Zaria, Nigeria
}

\author{
Anyebe Ada ${ }^{1}$ and Adam Adem Anyebe ${ }^{2 *}$ \\ 1Department of Christian Religious Studies, Federal College of Education, Zaria-Nigeria. \\ ${ }^{2}$ Department of Public Administration, Faculty of Administration, Ahmadu Bello University, Zaria-Nigeria. \\ *Corresponding author. Email: adamanyebe@gmail.com. Tel: 08035924309.
}

Copyright @ 2017 Ada and Anyebe. This article remains permanently open access under the terms of the Creative Commons Attribution License 4.0, which permits unrestricted use, distribution, and reproduction in any medium, provided the original work is properly cited.

Received 14th July, 2017; Accepted 1st August, 2017

\begin{abstract}
It has been observed that majority of students do not have effective study habit skills that are proportional to their academic demands. In recent times, reports of large scale academic failures among Nigerian students have become a subject of concern for stakeholders. Although, a lot have been written on study habits and academic performance of students in many areas but the effects of study habits on academic performance of CRS students seems to be a neglected area. This study, therefore, attempts to isolate time allocation and management as a factor of study habits and examine its effects on the academic performance of CRS students in Federal College of Education, Zaria. The following hypothesis that "there is no significant difference in the opinions of CRS students on the effects of time allocation and management on academic performance in Federal College of Education, Zaria" guided the study. Primary and secondary data used in the study were collected through Study Habit Inventory and other relevant materials. The primary data were analyzed using tables and simple percentages while independent t-test was employed to test the hypothesis. The results revealed that majority of CRS students at NCE level in Federal College of Education, Zaria used poor time allocation and management which was likely to have affected their academic performance. It was therefore recommended, among others, that students should be counseled on the effective time allocation and management.
\end{abstract}

Key words: Academic performance, networking, student, study habits, time allocation, time management.

\section{INTRODUCTION}

Christian Religious Studies is one of the major subjects missionaries bequeathed to Nigerian education system when they established schools in the 19th century. The teaching of the subject in our schools dates back to the first half of the nineteenth century when the Church Missionary Society (CMS) initiated teacher training in Nigeria in 1833 by establishing a teacher training institution in Abeokuta. This was closely followed by the establishment of a missionary school in Badagry in 1842 by the Christian missionaries. In 1896, CMS opened the Saint Andrew's College, Oyo. Since then, Christian Religious Studies (CRS) has remained an important subject in our school curriculum, and up till this moment, it is one of the core subjects taught in schools. In order to know students' ability in this subject, the students need to be examined because their academic performance forms an integral part in education as well as learning process.

The idea of testing or examining human abilities or characteristics goes back in time. The Bible records that the Gileadites used a one-item test during their war with the Ephramites to help detect enemy fugitives (Judges12:5-6). Each soldier who tried to cross the Jordan River was told to say the word shibboleth. Since the Ephramites pronounced it as siboleth, 42,000 of the enemy failed the test and were captured and put to death. It is a far cry from this primitive test to the sophisticated measuring instrument used in the twenty first century, but the principles remain the same, a person's behaviour is assessed either for purposes of selection or academic performance. 
Poor academic performance is one of the main problems of Nigeria educational system. For students to perform well in their academic pursuit, they need to study privately apart from the instructions given by their lecturers in the classrooms. There is a need for them to understand and recall what they have been taught and also read from other sources and this depends largely on their study habits.

It has been observed that majority of students do not have effective study habit skills that are proportional to their academic demands. In recent times, reports of large scale academic failures leading to the production of halfbaked and unemployable graduates from our higher institutions have become a subject of concern for stakeholders. For instance, Akpan (2013) conducted a doctoral research entitled "effect of study habits mediation package on senior secondary chemistry students' achievement and retention of electrolysis and concepts in Giwa education Zone, Kaduna State". His work was centered on the study habits and poor performance of students in the sciences. The main purpose of the study was to improve the study habits of male and female students. Three objectives were put forward by the researcher to assess the study habits of these students and how they affect the students' performance in Chemistry. In the methodology, the researcher used pre-test and post-test quasi experimental design. Descriptive and inferential statistics were used to analyse the data. The findings revealed among others, that there was a poor achievement and retention level of male and female students in the individual and group preference study habit categories. This study was conducted amongst secondary school students while the current study is to see if this can be applied to tertiary institution students.

Several factors are involved when it comes to study habits and academic performance of students and these include: proper time allocation and management, note taking, concentration during the hour of lecture, teacher consultation, study period procedures, examinations and written work, religious background of the students, social life, economic background of the students, organized study methods and location of the study activity. The difference between secondary and higher level of education is that, at secondary level, the students are expected to study what they have been taught in the class under a close supervision of the teacher. But at the tertiary level, the students however are expected to study independently. The students at this level have much freedom about the use of time. Under this condition, the students are left to decide what they should study at a particular time and how they should go about it. These students usually are faced with a variety of activities at the tertiary level and this is when the problem of choice comes in. For one to choose an activity and how to go about it requires the ability to organize oneself effectively.

Since the students have much freedom, they tend to waste much of this time on social activities such as face book, twitter and so on. Most of them usually hang around to chat with friends until late at night thereby forgetting to study. Some are so much involved in commercial activities at the expense of their academic work. Such students do not have the time to study and consult other sources of information to widen their scope. Others spend more time on social network than on their studies.

It has been observed by the researchers that in spite of the concerted efforts to improve the teaching and learning of CRS in colleges of education in Nigeria through the provision of equipped libraries and recruitment of qualified teachers by the school management, poor academic performance continue to be a reoccurring phenomenon and students continue to have difficulties in performing well academically as evidenced by their performances at the end of semester examinations. These students not performing well may be because of poor study habits. Majority of students are fully aware of the need to study, but the problem is that they do not know how to go about it and how to do it effectively, and this seems to affect their academic performance negatively.

The implication of this mass failure in colleges of education means that in the near future, there will be incompetent teachers to mount the educational industry for effective teaching and learning process. This will have negative effects on the achievement of our national objectives which is dependent on the quality and the number of qualified teaching personnel.

Although, a lot have been written on study habits and academic performance of students in many areas but the effect of study habit on academic performance of CRS students seems to be a neglected area. This study, therefore, attempts to isolate time allocation and management as a factor of study habits and examine its effects on the academic performance of CRS students in Federal College of Education, Zaria.

According to Khan (2016) allocating and managing one's time is an important factor in study. The issues of the time suitable for study, how long students should study and how to schedule study time have been tackled by different scholars. It is an art of allocating, organizing and budgeting the time for the purpose of creating more effective work and productivity. It has to do with students self-management with keen focus on time and then deciding on what to do, how to do it and how much time to allocate to these studying activities. Adebayo (2015) asserted that time allocation and management is a set of practice, principles, skills, tools and system that works together to help students get more values out of their time with the aim of improving the quality of their performance. It is a known fact that the study habits of students at any level of education improve and academic performance increases when time management skills are properly handled. 
Allocation and management of time is a skill which every student should know and apply to day to day academic life to solve academic problem. It is a concept that deals with problem solving and some of these problems are, being unable to deal with distraction, deadline pressure, and lack of self-discipline, procrastination and ambiguity of personal goals. Time is a priceless source and a single resource that cannot be accumulated for future use, cannot be changed, cannot be taken back once spent. No one can control the moving of time but everyone is able to decide how to use it. Time management is self-management with an explicit focus on time in deciding what to do, how much time to allocate to activities and when it is right for a particular activity to be carried out (Mercanlioglu, 2010). Students in tertiary institution are fond of complaining of running out of time whenever they are to perform certain task like assignment, test and exams. Such students are often frustrated because they are not able to finish the task ahead of them before the deadline. This most a time result into academic stress because student feel the pressure of rushing through assignment and cramming for exams and not getting enough sleep.

Supporting this is the work done by Bruce et al. (2013) that poor time management behaviours such as not allocating time properly or last minute cramming for exams are poor study habits that are sources of stress and poor academic performance. It is worthy to note that some of these students face a lot of challenges in their academic pursuit as a result of lack of organizational skills. They allow events that are not planned to interfere with their daily activities.

Al-Zoubi (2016) opined that the most crucial decision a student will make in tertiary institution is how to organize, allocate and make the best out of his time. This has to do with a student constructing a schedule and be able to reject pressure from friends and stay committed to the schedule as much as possible. Adding to this is the view of Burus et al. (2013) that time management schedule is one of the things that help students have a weekly routine that can bring about success in academic work and leisure activities. To them this schedule has to be systematically planned in a way to include activities during the week. This means that time should be allocated to review of notes before and after lectures and study activities after the day's classes.

Looking at students recently, the concept of time allocation and management seems to be one of the major crises they have especially regarding their academic and social life. These students in the process of carrying out their academic and social life are often overwhelmed with the feeling of there is no enough time to complete the task ahead. This happens because of lack of setting of goals and mismanagement of priorities which take most of their time and this affects their academic performance negatively. Al-Zoubi (2016) maintained that not managing time well is one of the factors affecting academic performance while effective time management is a good study habits that contributes to high academic achievement.

Time allocation and management can be affected by social networking. Social networking has been defined as a form of electronic communication through which users interact among themselves, create, share, exchange information, ideas, personal messages, and other content about each other using a multimedia mix of personal words, pictures, videos and audio (Michikyan, et al, 2015). Social networking is used to describe any website that enables users to create public profiles within that website and form relationship with other users of the same website who access their profile. It is used to describe community base website, online discussion forum, chat rooms and other social space online. Commonly, the phrase "social networking sites" is used as an umbrella term for all social media and computermediated communication, including but not limited to Facebook, Twitter, Linkedln, and Myspace, as well as the inaugural social networking sites of Cyworld, Bebo and Friendster. One of our respected traditional rulers, the Sultan of Sokoto, Alhaji Sa'ad Abubakar III, recently expressed concern at a development where social media is diverting attention of female (and male) students in the country at the closing ceremony of the sixth national education of the quaranic recitations competition in Sokoto. The sultan went further to say that: There is a disturbing development where the attention of students is being diverted from their studies through the use of various social others. The traditional ruler urged youths, particularly girls to stop spending too much time on social media at the expense of other engagements that would add more values to their lives (Abubakar, 2017:41).

The evolution and rapid advancement of social network sites has greatly impacted on peoples' communication on a daily basis. The growing dimension of the use of the social networking sites among our youth today cannot be over emphasized. Over the years, social networking among students has become more and more popular. It is a way to connect with other people, not only on campus but with friends outside the school. Social networking is a way that helps people feel they belong to a community. Due to the increase in popularity, scholars and educationist are now beginning to ask questions whether grades of students will not be affected by how much time is spent on these sites. Not only scholars and educationists, parents and guardians have also expressed their worries that students are spending so much time on Facebook and other social network sites and not having enough time to study. Confirming this fear is the work conducted by Choney (2010) which showed that the use of social networking sites such as Facebook and MySpace are most important factors that can influence the study habits and academic performance of students positively or adversely. This is because multitasking with these social networking sites can 
interfere with students learning process.

There is no doubt about the fact that the use of the social network has contributed positively to the academic performance of some students but some students also become poor academically. The darker side of social network sites evolution has resulted in dilemmas such as the setback of values of life among students who form the majority of users. These days most students have Facebook accounts so the reason why most of them perform poorly academically may not be farfetched. Though many people are quick to blame this on other factors, but they should try harder to reflect on the use of Facebook frenzy. Junco (2012) stated that students these days are so fascinated with the use of social networking sites that they are almost 24 hours online.

Good education produces outstanding students who will bring about the prosperity of their respective educational institution and subsequently are proved as strong contributors to the national well-being. Graeme (2010) opined that student users are affected by the internet and this impact is determined by the type of internet usage. They are positively affected by the informative use of internet while having drastic impact of recreational use of internet on them. Jonah (2013) also added that internet is advantageous to both students and teachers if used as a tool to create knowledge. The effect of social network sites usage will depend on the type of choice the student makes, if student uses the internet for the purpose of leisure activity that interferes with academic activities, it will affect the student academic performance negatively.

A research conducted by Kietzmann (2012) and Olowu and Seri (2012) found a continuing drop of grades among student users of social networking sites. However, many researchers also found a positive association between use of internet and social networking sites and academic performance of the student users. Students, using internet frequently, scored higher on reading skills, test and had higher grades as well. The following hypothesis will guide the study: There is no significant difference in the opinions of CRS students on the effects of time allocation and management on academic performance in Federal College of Education, Zaria.

\section{MATERIALS AND METHODS}

The research design adopted in this study is the survey research. The primary data were collected through an inventory and the secondary data from relevant materials. The total population of CRS students in Federal College of Education, Zaria is 1,640 and 437 students were identified as showing symptoms of poor study habits using Study Habit Inventory as designed, developed and standardized by Prof. C. G. M. Bakare. For purposes of in-depth study, $20 \%$ (or 87 ) of CRS students in Federal College of Education, Zaria were taken as the sample. 87 students were identified as showing signs of poor study habits and were therefore selected as the sample. These 87 students constitute $20 \%$ of the students showing signs of poor study habits was adjudged to be representative. This position can be supported by the view of Al-Zoubi (2016) on adequate sampling procedure who asserted that $20 \%$ of a population is an adequate sample.

For this study, study Habit Inventory (SHI) was used. This SHI was designed, developed and standardized by Professor C.G.M Bakare, a renowned educational psychologist, in 1977. The main purpose for using the Study Habit Inventory is that once ineffective study practices are known, necessary steps can be put in place to correct them. SHI is a self-report inventory which assists individual students to describe the situations, habits and conditions which affect their study habits and by extension academic performance. The inventory comprises 45 items that are in a form of direct questions. The students are required to respond on a five-point scale on how frequently they behave that way.

This inventory is divided into 8 sections $(A, B, C, D, E$, $F, G$ and $H$ ). Section $A$ deals with issues about Home Work and Assignments, B deals with issues about Time Allocations while $C$ dwells with issues on Reading and Note Taking. Section D takes care of issues about Period Procedures with section $\mathrm{E}$ dealing with issues about Concentration. Issues about Written Work are dealt with in section $F$ while sections $G$ and $H$ deal with issues about Examinations and Teacher Consultation respectively. Only section B was adopted for this study and copies of the inventory was randomly administered on the students using only odd-numbered students on the admission list.

The scoring is based on the fact that for each question, there are answers that portray desirable or effective study practices on the one hand, and undesirable or ineffective study practices on the other. Desirable practices should attract high scores while undesirable one attracts low scores. The scoring could be by the comprehensive form. In comprehensive form, the alternative answers are scored on a 5 point scale depending on whether it is a positive or negative. For Positive/Desirable Practice: Almost never $=1$; Less than half the time $=2$; Almost half the time $=3$; More than half the time $=4$; and Almost always $=5$. For Negative/Undesirable practice: Almost never $=5$; Less than half the time $=4$; Almost half the time $=3$; More than half the time $=2$; and Almost always $=1$.

The list of questions concerning students' habits and methods of study were administered to the students. The primary data were analyzed using tables and simple percentages while independent t-test was employed to test the hypothesis.

\section{RESULTS AND DISCUSSION}

Table 1 shows that 30 (or $34.5 \%$ ) of the 87 respondents 
Table 1. Time allocation and management.

\begin{tabular}{|c|c|c|c|c|c|}
\hline \multirow{2}{*}{ Questions } & \multicolumn{5}{|c|}{5 point scale } \\
\hline & 5 & 4 & 3 & 2 & 1 \\
\hline $\begin{array}{l}\text { Do you waste too much time talking or on social network at the } \\
\text { expense of your studies? }\end{array}$ & $\begin{array}{c}15 \\
(17.2 \%)\end{array}$ & $\begin{array}{c}10 \\
(11.5 \%)\end{array}$ & $\begin{array}{c}15 \\
(17.2 \%)\end{array}$ & $\begin{array}{c}20 \\
(23 \%)\end{array}$ & $\begin{array}{c}30 \\
(34.5 \%)\end{array}$ \\
\hline $\begin{array}{l}\text { Do you find that having many other things to do cause you to get } \\
\text { behind in your school work? }\end{array}$ & $\begin{array}{c}12 \\
(14 \%)\end{array}$ & $\begin{array}{c}15 \\
(17.2 \%)\end{array}$ & $\begin{array}{c}12 \\
(14 \%)\end{array}$ & $\begin{array}{c}20 \\
(23 \%)\end{array}$ & $\begin{array}{c}25 \\
(28.7)\end{array}$ \\
\hline $\begin{array}{l}\text { Do problems outside of the classroom-with other students or at home- } \\
\text { cause you to neglect your school work? }\end{array}$ & $\begin{array}{c}10 \\
(11.5 \%)\end{array}$ & $\begin{array}{c}10 \\
(11.5 \%)\end{array}$ & $\begin{array}{c}12 \\
(14 \%)\end{array}$ & $\begin{array}{c}25 \\
(28.7)\end{array}$ & $\begin{array}{c}30 \\
(34.5 \%)\end{array}$ \\
\hline Do you study for at least three hours each day after classes? & $\begin{array}{c}17 \\
(19.5)\end{array}$ & $\begin{array}{c}15 \\
(17.2 \%)\end{array}$ & $\begin{array}{c}15 \\
(17.2 \%)\end{array}$ & $\begin{array}{c}35 \\
(40.0 \%)\end{array}$ & $\begin{array}{c}25 \\
(28.7 \%)\end{array}$ \\
\hline $\begin{array}{l}\text { Is your time unevenly distributed; do you spend too much time on } \\
\text { some subjects and not enough on others? }\end{array}$ & $\begin{array}{c}16 \\
(18 \%)\end{array}$ & $\begin{array}{c}16 \\
(18 \%)\end{array}$ & $\begin{array}{c}13 \\
(15 \%)\end{array}$ & $\begin{array}{c}37 \\
(42.5 \%)\end{array}$ & $\begin{array}{c}35 \\
(40 \%)\end{array}$ \\
\hline $\begin{array}{l}\text { Do you spend too much time reading fiction (novels), going out etc, for } \\
\text { the good of your school work? }\end{array}$ & $\begin{array}{c}10 \\
(11.5 \%)\end{array}$ & $\begin{array}{c}15 \\
(17.2 \%)\end{array}$ & $\begin{array}{c}15 \\
(17.2 \%)\end{array}$ & $\begin{array}{c}24 \\
(27.5 \%)\end{array}$ & $\begin{array}{c}23 \\
(26.4 \%)\end{array}$ \\
\hline
\end{tabular}

Source: survey, 2017.

agreed that they almost always waste much time talking or on social network at the expense of their studies while 20 (or $23 \%$ ) said they spend more than half of their time on these activities to the detriment of their studies. Only 15 (or $17.2 \%$ ) indicated that they almost never waste much time talking or on social network and 10 (or 11.5\%) engaged less than half of their time in these activities. However, 15 (or 17.2\%) of the respondents said they engage in these activities (media like Facebook, Twitter, WhatsApp, 2go and Instagram and among) about half of their time. The number and percentage of respondents as regards their opinions on each of the questions about time allocation and management is indicated in Table 1.

Using independent t-test (a parametric test), the null hypothesis which states that "there is no significant difference in the opinions of CRS students on the effects of time allocation and management on academic performance in Federal College of Education, Zaria" was tested.

As obtained from the result, Group A consists of students always showing study habit problems and Group B consists of students exhibiting the problems less often.

\begin{tabular}{ll}
\hline A & B \\
\hline 50 & 25 \\
45 & 27 \\
55 & 20 \\
60 & 32 \\
72 & 32 \\
$\underline{47}$ & 25 \\
329 & 161 \\
\hline
\end{tabular}

Process showing calculation of frequency of $A$.

\begin{tabular}{lll}
\hline $\mathbf{X}$ & $\mathbf{X}-\dot{\mathbf{X}}$ & $(\mathbf{X}-\dot{\mathbf{X}})^{\mathbf{2}}$ \\
\hline 50 & -4.83 & 23.32 \\
45 & 09.83 & 96.63 \\
55 & 0.17 & 0.03 \\
\hline
\end{tabular}

\begin{tabular}{lll}
\hline 60 & 5.17 & 26.73 \\
72 & 17.17 & 294.81 \\
47 & -7.83 & 61.31 \\
329 & & 502.83 \\
\hline
\end{tabular}

Mean $\dot{X}=\frac{329}{6}=54.83$

Variance $=\frac{502.83}{6}=83.81$

S. $D=\frac{\sqrt{502.83}}{6}=9.15$

Process showing calculation of frequency of $B$.

\begin{tabular}{lll}
\hline $\mathbf{X}$ & $\mathbf{X}-\dot{\mathbf{X}}$ & $(\mathbf{X}-\dot{\mathbf{X}})^{2}$ \\
\hline 25 & -1.8 & 3.24 \\
27 & 0.2 & 0.04 \\
20 & -6.8 & 46.24 \\
32 & 5.2 & 27.04 \\
32 & 5.2 & 27.04 \\
25 & -1.8 & 3.24 \\
161 & & 106.84 \\
\hline
\end{tabular}

Mean $\dot{X}=\frac{161}{6}=26.8$

Variance $=\frac{106.84}{6}=27.8$

S. D $=\frac{\sqrt{502106.84 .83}}{6}=4.22$

\section{Student $\mathrm{t}$-test}

The student $\mathrm{t}$-test was obtained using the formula: 
$\mathrm{t}=\frac{(\dot{\mathrm{X}}-\dot{\mathrm{X}} 2)}{\sqrt{\delta_{1}^{2}+\delta_{2}^{2}}} / \mathrm{n}$

Where; $\dot{\mathrm{X}}_{1}=$ mean of $(\mathrm{A}), \dot{\mathrm{X}}_{2}=$ mean of $(\mathrm{B}), \delta 1=$ Standard Deviation of $(\mathrm{A})$ and $\delta 2=$ Standard Deviation of $(\mathrm{B})$

$t=\frac{(54.83-26.8)}{\sqrt{83.72+17.81}} / 6$

$\mathrm{t}=6.81$

\section{Degree at freedom}

The Degree at freedom was obtained using the formula:

$$
\begin{aligned}
\mathrm{df} & =n 1+\mathrm{n} 2-1 \\
\mathrm{df} & =6+6-2 \\
& =10
\end{aligned}
$$

The results are as follows: calculated value is 6.81 , critical value is -1.812 at 0.05 level of significance and at 10 degree of freedom. Since the calculated value of t-test is greater than critical value of distribution table the null hypothesis is rejected. This means the alternate hypothesis that there is a significant difference in the opinions of CRS students on the effects of time allocation and management on academic performance in Federal College of Education, Zaria is accepted.

This result is in agreement with the work of Bruce et al. (2013) that poor time management behaviours such as not allocating time properly or last minute cramming for exams are poor study habits that are sources of stress and poor academic performance. It is worthy to note that some of these students face a lot of challenges in their academic pursuit as a result of lack of organizational skills. They allow events that are not planned to interfere with their daily activities. It is also in consonance with the opinion of Al-Zoubi (2016) that the most crucial decision a student makes in tertiary institution is how to organize, allocate and make the best out of their time. This has to do with a student constructing a schedule and be able to reject pressure from friends and stay committed to the schedule as much as possible. The findings also agreed with the view of Burus et al. (2013) that time management schedule is one of the things that help students have a weekly routine that can bring about success in academic work and leisure activities.

The study findings also agreed with the view of Abubakar (2017) who expressed concern that the rate at which students spend time on social network is worrisome and may pose imminent danger to our society. This poor time allocation and management is likely to affect academic performance of the students as expressed by the respondents in the study. In a situation where students spend substantial part of their time on non-essential things at the expense of their studies is worrisome as indicated by the opinions of the respondents. Table 1 indicated that the students waste too much time talking or on social network at the expense of their studies. $23 \%$ and $34.5 \%$ respectively, of the students indicated that more than half of the time and most of the time they waste their time talking or on social network at the expense of their studies. This definitely will have implications for their academic performance.

\section{Conclusions and Recommendations}

From the discussion, one inescapable conclusion is that since the CRS students at NCE level in Federal College of Education, Zaria have much freedom they tend to waste much time on non-essential things to the detriment of their studies. This habit may eventually affect their academic performance negatively. It is therefore, recommended that since time is a scarce resource and once used cannot be recovered, students should be taught to allocate and manage their time effectively for enhanced academic performance. Orientation programmes should be organized by the college management regularly, for CRS students on the use of time. Further studies are recommended in areas of effect of socio economic background of parents as well as absenteeism on academic performance of students in our higher institutions.

\section{CONFLICT OF INTEREST}

The authors declare that they have no conflict of interest.

\section{REFERENCES}

Abubakar, S. (2017). Social Media Diverting Attention of Girls from Studies. Daily Sun, Monday, July 10, 2017. Available online at www.sunnewsonline.com

Adebayo, F. A. (2015). Time Management and Students' Academic Performance in Higher Institutions in Nigeria. A Case Study of Ekiti State. International Research in Education, 3(2), 1-12.

Akpan, J. O. (2013). Effect of a Study Habit Mediation Package on Senior Secondary Chemistry Students. Achievement and Retention of Electrolysis Concepts in Giwa Educational Zone, Kaduna State. Unpublished Ph.D Dissertation Submitted to the School of Postgraduate Studies, Ahmadu Bello University, Zaria.

Al-Zoubi, M. (2016). The effect of time management art on academic achievement among high school students in Jordan. Journal of Education and Practice. 7(5), 106-110.

Burrus, J., Jackson, T., Holtzman, S., Roberts, R. D., \& Mandigo, T. (2013). Examining the efficacy of a time management intervention for high school students. ETS Research Report Series, 2013(2), 13-25.

Judges (12:5-6). The Holy Bible

Khan, Z. N. (2016). Factors Affecting Study Habbits. World 
Journal of Educational Research, 3(1), 145.

Mercanlioglu, L. (2010). The relationship between time management and academic performance of masters' level students. International Journal of Business and Management Studies. 2(1), 25-36.

Michikyan, M., Subrhmanyan, K., \& Denis, J. (2015). Facebook use and academic performance among college students: A Mixed Methods Study with a Multi-Ethnic Sample. Computer in Human Behaviour, 5(1), 265-271.
Kietzmann, H. (2012). Social Media? Get Serious. Understanding the functional building blocks of social media. Business Horizone, 54(1), 241-251.

Olowu, A. O., \& Seri, F. O. (2012). A study of social network addiction among youths in Nigeria. Journal of Social Science and Policy, 9(3), 904-100. 